\title{
SCIENCE, TECHNOLOGY AND INNOVATION
}

\author{
INTEGRATED TREATING QUALITY \\ INDICATOR OF GAS FROM ACID \\ COMPONENTS IN ETHYLENE
}

\author{
ALISHER SULTANOV \\ Shurtan Gas and Oil Plant, Uzbekistan \\ SAIDAKBAR ABDURAKHIMOV \\ Institute of the Higher Engineering \\ Pedagogics, Tashkent State Technical \\ University \\ ZOKIRJON SALIMOV \\ Institute of General and Inorganic \\ Chemistry, Uzbekistan
}

UDC: 66.07

Keywords: Manufacture of ethylene, gas clearing, dioxide carbon, dioxide nitrogen, mercaptan, optimization, number of Wobbe, Harrington function

\begin{abstract}
Possibilities of the decision of compromise problems with using of complex indicators of quality for optimization of technological modes of clearing of raw gas in manufacture ethylene are resulted.
\end{abstract}

Source: Sultanov A., Abdurakhimov S., Salimov Z., 2012. "Integrated treating quality indicator of gas from acid components in ethylene", Perspectives of Innovations, Economics \& Business, Vol.12(3), pp.97-102, http://dx.doi.org/10.15208/pieb.2012.20

\section{Introduction}

It is known that quality of natural gas to be supplied to pipelines is standardized by Industry Standard OST (otraslevoy standart - Rus.) 51.40-74.

Table 1 shows rates of moderate and hot climatic zones as well as for cold climatic zones of different countries (OST, 1974).

Unfortunately, today carbon dioxide and nitrogen contents in natural gas that is transported through gas pipeline is not standardized. These indices significantly affect on Wobbe constant which is in accordance with International Gas Union requirements shall change in narrow range from 1100 to $12000 \mathrm{kcal} / \mathrm{m}^{3}\left(46057-50244 \mathrm{~kJ} / \mathrm{m}^{3}\right)$. Therefore, content of carbon dioxide and nitrogen in gas pipeline does not exceed 2 and 4\%, respectively. Hydrogen sulfide, organic sulfur compounds, mainly mercaptans are contained in natural gas. Permissible mercaptans rate is based on quality of injected ethyl mercaptan as an odorant. Amount of its injection is $18 \mathrm{mg} / \mathrm{m}^{3}$. Such concentration corresponds to human sensitivity to $1 \%$ gas in air which for 4 times less of explosive concentration. 
TABLE 1. NATURAL GAS INDICES SUPPLIED TO PIPELINES

\begin{tabular}{lcc}
\hline Description of indices & \multicolumn{2}{c}{ Rate values } \\
\cline { 2 - 3 } & $\begin{array}{c}\text { for moderate and hot } \\
\text { climatic zones }\end{array}$ & $\begin{array}{c}\text { for cold } \\
\text { climatic zones }\end{array}$ \\
\hline $\begin{array}{l}\text { Dew point and heavy hydrogen at } 5.5 \\
\text { MPa, }{ }^{\circ} \mathrm{C} \text { (not more than) }\end{array}$ & -10 & \\
\hline - in winter period & -3 & -25 \\
\hline - in summer period & 0.1 & -15 \\
\hline $\begin{array}{l}\text { Content of mechanical impurities: } \\
\text { g/100 } \text { m }^{3} \text { of gas (not more than) }\end{array}$ & 2.0 & 0.1 \\
$\begin{array}{l}\text { Content of hydrogen sulfide } \\
\text { g/100 } \text { m }^{3} \text { of gas (not more than) }\end{array}$ & 1.0 & 2.0 \\
\hline Content of oxygen: \% (not more than) & & 1.0 \\
\hline
\end{tabular}

\section{Analysis}

Today, due to pipeline transfer to pressure at 7.5 MPa, standards of OST 5140-74 shall be changed. In this case, dew point for cold climatic zone in winter and for hot climatic zone in summer shall be reduced up to 23 and $14^{\circ} \mathrm{C}$, respectively. Moisture content in this shall be lower 0.022 and $0.044 \%$, respectively.

There is no doubt that these indices are different from foreign standards where transportation and natural gas processing specifics are considered. For instance, in USA hydrogen sulfide content is standardized at the level of 5.7 $\mathrm{mg} / \mathrm{m}^{3}$. By agreement with gas transportation companies, $\mathrm{CO}_{2}$ content may reach $+2 \%$, mercaptans $1.5-5.0 \mathrm{mg} / \mathrm{m}^{3}$, total sulfide content $22-228 \mathrm{mg} / \mathrm{m}^{3}$ (OST, 1978).

Natural gas supply to consumers according to standard OST 5542-78 varies in the following ranges:

- Wobbe number - 39400-5200 kJ/m³

- deviation of Wobbe number - $\pm 5 \%$

- hydrogen sulfide content - not more than $20 \mathrm{mg} / \mathrm{m} 3$

- sour sulfur content - not more than $36 \mathrm{mg} / \mathrm{m} 3$

- oxygen content - not more than $1 \%$

- mechanical impurities content - not more than $1 \mathrm{mg} / \mathrm{m} 3$

- combustion limit with air - 4-15 volume

- spontaneous ignition temperature - not less than $723 \mathrm{~K}$.

Wide use of chemisorption method is found for natural gas sweetening from hydrogen sulfide and carbon dioxide which of them is amine method. Within last years, diethanolamine (DEA) in aqueous solution is tending to use at concentration of $25-30 \%$.

As it is shown, in natural gas composition except hydrocarbon it contains mechanical impurities like hydrogen sulfide, carbon dioxide and nitrogen, 
mercaptans, oxygen, moisture and other compounds that negatively affect on the quality of produced products. Reduction of their content is undoubtedly promoting to increasing of stable functioning of processing line of complex processing of raw gas and its technical and economical indices.

It is known that for optimization of such multi parametric processes it is appropriate to use integrated quality index of raw gas processing which is formed on the basis of principles and methods of qualimetry (Kafarov, 1976). Hence, quality of raw gas treating is characterized by two stages: first assessment of individual indices of raw as processing and second - integrated assessment of quality of raw gas treatment by single parameter (Kafarov, 1976; Panfilov, 1986).

For assessment of such indices it is appropriate to use dimensionless relative treating quality indices of raw gas and coefficients of their cogency since individual indices are not equal by its significance.

\section{Results and discussion}

Abovementioned indices of natural gases may be classified in two groups: physical-chemical and technological.

These indices may be converted into dimensionless values according to Harrington function given in Figure 1.

Such conversion of natural indices of raw gas treatment quality into dimensionless values allows in the sequel quantitatively assessing of functioning efficacy of considered chain and revealing it's the best operating practice. For processing of received information on quality of raw gas treatment there are series of methods based on use of weightiness coefficients of studied indices.

There are known assessment methods of integrated indices of raw gas treatment quality by means of grouping of single-type indices o determination in them arithmetical mean values and summation of the latter by groups taking into account their weightiness coefficient.

However, such method of calculation smoothes minor deviations of quality indices and promotes to increasing of functioning stability of studied chain.

Figure 2 shows flow chart of calculation algorithm and optimization of integrated quality index of raw gas treatment in ethylene production. So, integrated quality index of raw gas treatment in ethylene production is calculated by formula:

$$
\text { Di }=\sqrt{d_{1}, d_{2}, \ldots, d_{i}}
$$

where $d_{i}$ - is dimensionless coefficient of $i$ - index; $n$ - quantity of partial indices.

Here, the following inequality shall be followed:

$$
0.0<d_{n i}<1.0
$$




\section{Conclusion}

By using of integrated quality index of raw gas treatment in ethylene production, trade-off problem may be solved for optimization of its operating practices.

Thus, designed integrated quality index of raw gas treatment based on Harrington function and arithmetic mean value allows significantly reducing of volume calculation procedures by selection of optimal conditions of realization of studied processes and increasing their reliability.

\section{References}

Kafarov, V., 1976. Cybernetics methods in chemistry and chemical technologies [Metody kibernetiki v himii i himicheskoy tehnologii],in Russian, Edition 3, Moscow: Himia

OST, 1974. Industrial standard 51.40-74. Technical specifications. Natural gases transported through pipelines [Otraslevoy standart OST 51.40-74. Tehnicheskie usloviya. Prirodnye gazy transportiruemye po truboprovodu], in Russian, Moscow: Standards of 1974, p.11

OST, 1978. Industrial standard 5542-78. Technical specifications. Natural gas supplied to consumers [Tehnicheskie usloviya. Prirodnyj gaz, podavaemyj potrebitelyam], in Russian, Moscow: Standards of 1978, p.9

Panfilov, V., 1986. Scientific bases of development of processing line production [Nauchnye osnovy razvitiya tehnologicheskih liniy proizvodstv], in Russian, Moscow: Agropromizdat 


\section{Appendix}

FIGURE 1. GRAPH-ANALYTIC METHOD OF CONVERSION OF QUALITATIVE INDEX OF PURIFIED GAS INTO DIMENSIONLESS VALUES BASED ON HARRINGTON FUNCTION

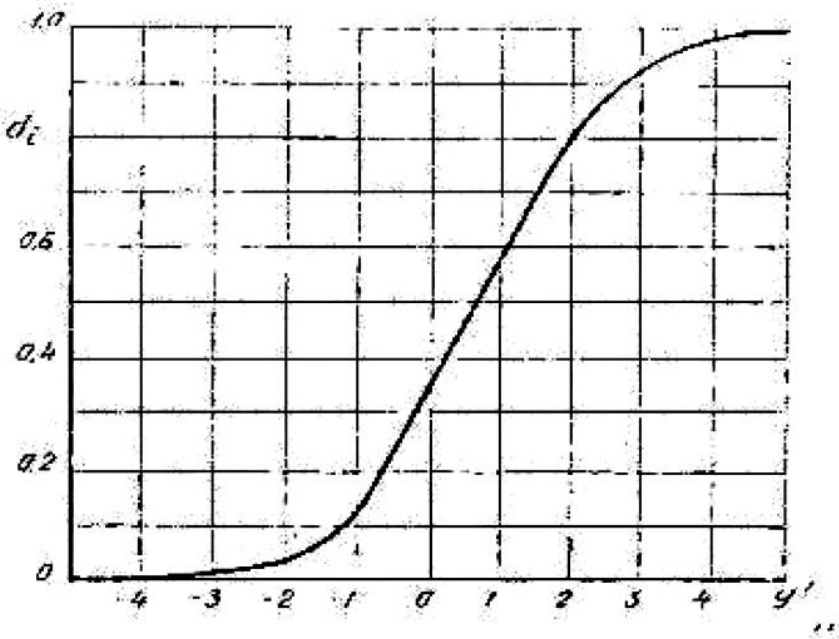


FIGURE 2. FLOW CHART OF CALCULATION ALGORITHM OF OPTIMIZATION OF INTEGRATED QUALITY INDEX OF RAW GAS TREATMENT IN ETHYLENE PRODUCTION

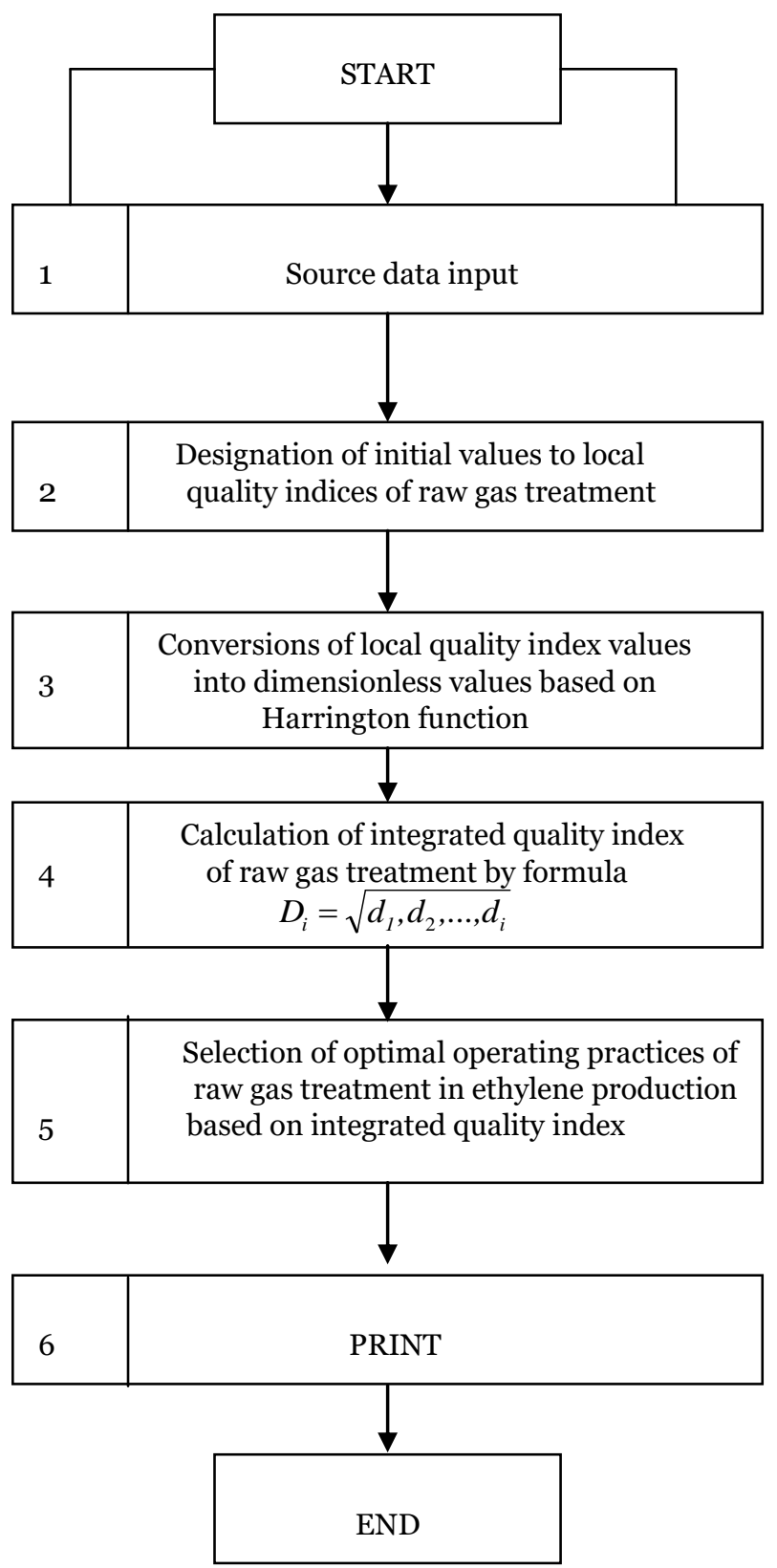

